\title{
Potencial antimicrobiano de diferentes retentores intrarradiculares frente a Enterococcus faecalis: uma avaliação in vitro
}

\author{
Evaluation of antibacterial activity of different intraradicular retainers against \\ Enterococcus faecalis: in vitro evaluation
}

Nicole Hoffmann FINGER ${ }^{a}$ (D) Marília PAULUS $^{a}$ [i], Alexandra Flávia GAZZONI ${ }^{a *}$ (1)

${ }^{a}$ FSG - Centro Universitário, Curso de Graduação em Odontologia, Caxias do Sul, RS, Brasil

Como citar: Finger NH, Paulus M, Gazzoni AF. Potencial antimicrobiano de diferentes retentores intrarradiculares frente a Enterococcus faecalis: uma avaliação in vitro. Rev Odontol UNESP. 2019;48:e20190051. https://doi.org/10.1590/18072577.05119

\begin{abstract}
Resumo
Introdução: 0 tratamento endodôntico tem como objetivo erradicar microrganismos bacterianos e fúngicos do canal radicular, ou pelo menos possibilitar sua redução para níveis compatíveis com a saúde do tecido perirradicular, uma vez que, após o tratamento endodôntico, colônias de microrganismos residuais podem estar presentes nos túbulos dentinários e no cemento. Objetivo: Avaliar o potencial antimicrobiano de diferentes tipos de retentores intrarradicularess em dentes bovinos. Material e método: 50 dentes unirradiculares após tratamento endodôntico concluído foram desobturados, bem como tiveram seus condutos preparados para a cimentação dos retentores intrarradiculares. Posteriormente, os dentes foram contaminados por Enterococcus faecalis por meio da montagem de um dispositivo, o qual permitiu a infiltração bacteriana. Os dados resultantes da contagem das Unidades Formadoras de Colônia foram analisados utilizando o teste de ANOVA one-way, seguido pela análise de comparações múltiplas de Tukey. Resultado: Decorrido o período de 14 dias, o grupo que apresentou a maior infiltração bacteriana foi o grupo-controle, o qual não continha nenhum tipo de retentor intrarradicular, seguido do G1-FV (grupo de continha retentor radicular de fibra de vidro) e G2-FC (grupo de que continha retentores radiculares de fibra de carbono). $\mathrm{O}$ menor grau de recuperação bacteriana foi encontrado nos grupos $\mathrm{G} 3-\mathrm{Ni}$-Cr e $\mathrm{G} 4-\mathrm{Cu}-\mathrm{Al}$, os quais continham retentores intrarradiculares metálicos formados por ligas de níquel-cromo e cobrealumínio, respectivamente. Conclusão: Os retentores aqui avaliados apresentam diferentes efeitos antimicrobianos. Assim, a utilização de um pino com melhores resultados antimicrobianos favorece maiores chances de sucesso nos tratamentos reabilitadores.
\end{abstract}

Descritores: Endodontia; técnica para retentor intrarradicular; infiltração dentária; obturação do canal radicular.

\begin{abstract}
Introduction: The ultimate goal of endodontic treatment is the eradication of microorganism from the root canal space, or at least their reduction to levels compatible with periradicular tissue health since after endodontic treatment colonies of residual microorganisms may be present in the dentinal tubules and cementum. Objective: To evaluate the antibacterial activity of different fiber posts in the root canal system of bovine teeth. Material and method: Here, 90 uniradicular bovine teeth were randomly assigned after complete endodontic therapy. The samples were unthreaded, as well as had their conduits prepared for the cementation of the intracanal retainers. Subsequently, the teeth were exposed to Enterococcus faecalis by means of the assembly of a device, which allowed bacterial infiltration. The data of the amount by colony forming unit (CFU) per ml assay were analyzed by one-way ANOVA followed by Tukey's HSD post hoc test $(p<0,05)$. Result: After the 14-day period, the group that presented the highest bacterial infiltration was the control group, which did not contain any type of intrarradicular retainer, followed by G1-FV (group of contained fiber glass post) and G2- FC (group containing carbon fiber reinforced post). Results of the smallest degree of bacterial recovery was found in the $\mathrm{G} 3-\mathrm{Ni}-\mathrm{Cr}$ and $\mathrm{G} 4-\mathrm{Cu}-\mathrm{Al}$ groups, which contained metallic
\end{abstract}


intracanal retainers by nickel-chromium and copper-aluminum alloys respectively. Conclusion: The intracanal retainers evaluated here presented different antimicrobial effects. Thus, the use of intracanal post with better antimicrobial results, favors greater chances of success in rehabilitation treatments.

Descriptors: Endodontics; post and core technique; dental leakage; root canal obturation.

\section{INTRODUÇÃO}

A presença de microrganismos no interior do canal radicular está fundamentada na literatura pela existência de mais de 400 espécies diferentes de bactérias, as quais estão relacionadas a diversos tipos de infecções endodônticas, uma vez que estas são classificadas de acordo com sua localização: intrarradicular ou extrarradicular ${ }^{1,2}$. Por sua vez, o canal radicular é considerado uma via, a qual se caracteriza por ser suscetível a infecções bacterianas. Esta particularidade está associada à baixa resistência do hospedeiro frente às agressões físicas, químicas e biológicas, assim como à necrose pulpar decorrente de cáries, doença periodontal, trauma e iatrogênias 3 . Nesse contexto, o Enterococcus faecalis, um diplococo Gram-positivo, é constantemente associado às lesões radiculares, principalmente àquelas consideradas como refratárias, uma vez que esta característica se deve à sua grande resistência às substâncias antimicrobianas, bem como à sua intensa capacidade de formar biofilme ${ }^{4,5}$.

Em vista disso, o tratamento endodôntico tem como objetivo primordial a remoção de depósitos microbianos formadores de biofilme do sistema de canais ${ }^{5-7}$. Não obstante, devido tratamento endodôntico prévio, fratura ou amplas restaurações, o remanescente dentário encontra-se fragilizado, com escassa porção coronária. Perante isso, a confecção de restaurações para recuperação de forma, função e estética, e proteção do remanescente torna-se necessária. Neste cenário, a utilização de retentores intrarradiculares (RIR) fundamenta-se no auxílio da retenção e do suporte da futura restauração, uma vez que tal prescrição está associada a grandes perdas de estrutura dentária e fragilização do canal radicular8-10.

Entretanto, falhas no tratamento endodôntico ou na confecção dos pinos intracanais transcorrem devido à ruptura nos princípios biológicos, uma vez que microrganismos usualmente penetram no sistema de canais radiculares no período entre as consultas ou até mesmo após a finalização do tratamento endodôntico ${ }^{1,5,6}$. Para além disso, após o tratamento de canais radiculares, a quantidade de microrganismos diminui significativamente. Porém, o retorno de características de esterilidade dos tecidos infectados é impossível, devido ao fato de que não há eliminação de $100 \%$ dos agentes microbianos ${ }^{1,11}$. Neste contexto, vale ressaltar que há a possibilidade de manutenção do crescimento microbiano no interior do sistema de canais radiculares mesmo após o tratamento endodôntico. Embora muitas melhorias tenham sido alcançadas durante a extensão longitudinal temporal no que diz respeito aos protocolos de químico-mecânica endodôntica, a desinfecção usada hoje não pode rigorosamente fornecer a esterilidade do complexo do canal radicular ${ }^{12}$. Adicionado a isso, e de extrema relevância, há o fato de que nenhum dos elementos da terapia endodôntica (sistema de defesa do hospedeiro, instrumentação e irrigação, medicamentos intracanal, restauração radicular permanente e restauração coronária) pode garantir a desinfecção completa ${ }^{13-23}$.

Por conseguinte, a incorporação de estruturas apresentando características antimicrobianas no canal radicular torna-se um fator primordial na prevenção do recrescimento de bactérias residuais. Neste âmbito, retentores intracanais reforçados com algum tipo de material antimicrobiano têm sido interessantemente alvos de estudos ${ }^{16-19}$. No entanto, até o presente momento, nenhum estudo avaliou as propriedades antibacterianas dos pinos reforçados com fibra de vidro, fibra de carbono e metálico fundido, em dentes bovinos.

Dada a importância do E. faecalis nos casos de insucesso endodôntico e a utilização dos RIR, e a falta de estudos a respeito, este estudo avaliou o potencial antimicrobiano de diferentes tipos de retentores intracanais frente a este microrganismo. 


\section{MATERIAL E MÉTODO}

\section{Características dos Pinos}

Para realização do estudo, foram utilizados quatro tipos distintos de retentores intrarradiculares. Tais pinos foram randomizados e seguiram uma distribuição conforme informado na Tabela 1.

Tabela 1. Subdivisão dos grupos do estudo conforme a constituição de cada pino intra-radicular

\begin{tabular}{ccc}
\hline Grupo & Modelo de Pino & $\begin{array}{c}\text { Quantidade de dentes } \\
\text { avaliados }\end{array}$ \\
\hline G1-FV & Fibra de vidro Reforpost no3 & 10 \\
G2-FC & Fibra de carbono Reforpost nº3 & 10 \\
G3-Ni-Cr & Núcleo metálico em ligas de Ni-Cr & 10 \\
G4-Cu-Al & Núcleo metálico em ligas de Cu-Al & 10 \\
G5 & Dentes tratados endodonticamente sem a presença de pino intra-radicular & 10 \\
\hline
\end{tabular}

FV: Fibra de vidro; FC: Fibra de carbono; Ni-Cr: Níquel-cromo; Cu-Al: Cobre-alumínio.

\section{Seleção e Preparo dos Espécimes}

Neste experimento, foram utilizados 50 dentes incisivos inferiores bovinos, os quais foram extraídos e armazenados em água destilada. Para seleção de cada dente, utilizou-se o critério da similaridade da morfologia externa e interna de dentes de animais adultos, a qual foi avaliada por meio de radiografias periapicais. Subsequentemente, seguiu-se a metodologia proposta por Haapasalo, Orstavik $^{24}$ (1987) para limpeza e desinfecção de tais dentes. Assim, os dentes foram limpos com curetas Gracey (Quinelato Qualidade, Rio Claro, Brasil) e profilaxia com pedra pomes, e em seguida foram armazenados em solução de cloramina T 0,5 (Merck Millipore, Massachusetts, EUA).

Para o preparo dos espécimes, foram realizados dois cortes transversais com disco diamantado de dupla face. 0 primeiro, realizado a $5 \mathrm{~mm}$ aquém do ápice radicular, e o segundo, a partir da coroa, a fim de providenciar um segmento radicular com $15 \mathrm{~mm}$ de comprimento. Em sequência, a polpa foi removida do canal radicular com limas endodônticas tipo Kerr (AllPrime Dental, Brasília, Brasil) sob constante irrigação com hipoclorito de sódio ( $\mathrm{NaOCl}$ ) (1\%) (Asfer Indústria Química, São Caetano do Sul, Brasil), para suspensão da matéria orgânica. Posteriormente, as raízes foram mantidas em ambiente úmido, submersas em soro fisiológico ( $\mathrm{NaCl}$ 0,9\%) estéril (Fresenius Medical Care, Rio de Janeiro, Brasil) a $10^{\circ} \mathrm{C}$, para evitar desidratação.

\section{Tratamento Endodôntico}

As raízes foram instrumentadas através da técnica escalonada utilizando-se limas tipo $\mathrm{K}$ (AllPrime Dental Products, Brasília, Brasil). Estas seguiram a sequência crescente de no 90 a 140, em movimentos de limagem em todo o comprimento do canal e irrigação contínua com $\mathrm{NaOCl}$ (1\%). Ao final, foi realizada irrigação abundante utilizando $20 \mathrm{~mL}$ de soro fisiológico. Novamente, adotaram-se os mesmos procedimentos de armazenamento citados anteriormente para todos os grupos do estudo.

Em virtude do calibre dos canais, houve a necessidade prévia de confecção do cone principal, elaborado pela união de dois cones de guta-percha no 80 (AllPrime Dental Products, Brasília, Brasil). Para alcançar adequada adaptação do cone principal no forame apical, nas situações em que este se projetou para fora da região apical, procedeu-se pelo corte do cone nessa região. Após inserção do cone principal com cimento endodôntico Fillcanal (Technew, Rio de Janeiro, Brasil) 
no interior do canal radicular, os cones acessórios foram introduzidos (Tanari, Manaus, Brasil) com auxílio de um condensador de guta-percha no 35 (Mani, Rio de Janeiro, Brasil). Posteriormente, a porção excedente dos cones de guta-percha foi cortada e, em seguida, condensada verticalmente com instrumentos calcadores aquecidos tipo Paiva (Golgran, São Caetano do Sul, Brasil). Subsequentemente, com o objetivo de remover quaisquer resíduos de material obturador, tanto o canal radicular quanto a porção externa radicular foram limpos com álcool $70^{\circ}$ (Simoquímica, Caxias do Sul, Brasil). Para confirmação da qualidade da obturação e do nível de corte, realizaram-se radiografias periapicais dos dentes obturados.

\section{Inserção de Pinos Intrarradiculares}

O espaço para a inclusão dos retentores intracanais foi obtido imediatamente após a conclusão de suas obturações. Utilizando-se o calcador de Paiva aquecido ao rubro, foi removido o material obturador, de forma que restassem de 3 a $4 \mathrm{~mm}$ de guta-percha apical. Posteriormente, foi realizada radiografia de confirmação do corte de material obturador. Em seguida, o canal radicular foi limpo e seco com pontas de papel absorvente no 80 (Tanari, Manaus, Brasil). Os retentores foram limpos com microbrush KG Sorensen (Cotia, São Paulo, Brasil) e embebidos com álcool 70\%. Adicionalmente, somente naqueles espécimes pertencentes ao G1-FV, foi realizada a aplicação de silano. Para cimentação, utilizou-se o cimento autoadesivo RelyX U200 (3M, São Paulo Brasil). 0 mesmo foi introduzido no canal com o auxílio de uma lima, bem como foi pincelado na superfície do pino, o qual foi inserido no interior do canal e, em seguida, fotopolimerizado de acordo com as instruções do fabricante.

\section{Confecção do Dispositivo para Teste de Infiltração Bacteriana}

Para confirmar a passagem do E. faecalis por meio da obturação, foi elaborado um dispositivo: os espécimes foram inseridos na porção inferior de microtubos tipo Eppendorf (CRAL, Cotia, Brasil) com capacidade para 1,5 mL. Com o auxílio de um disco de carburundum (Dentorium, Nova Iorque, EUA), foi realizado um corte transversal, a fim de remover o fundo dos microtubos e, assim, possibilitar a adaptação dos espécimes, uma vez que este procedimento permitiu que $2 \mathrm{~mm}$ da extremidade apical da raiz se projetasse para fora do mesmo. Com o objetivo de fixar o espécime e de impedir a passagem do meio de cultivo nessa região, a junção entre o microtubo e a raiz foi selada com cola araldite de presa rápida (Huntsman Advanced Materials, Taboão da Serra, Brasil). Subsequentemente, após excluir $1 \mathrm{~mm}$ circundante ao extremo apical, a porção do segmento externo do microtubo foi recoberta com duas camadas de esmalte para unhas (Colorama Esmaltes, São Paulo, Brasil). Esse procedimento foi realizado com o objetivo de impermeabilizar as raízes lateralmente.

Após a montagem deste dispositivo, todo o conjunto foi submetido ao processo de esterilização em autoclave a $127^{\circ} \mathrm{C}$ por 15 minutos.

\section{Microrganismo}

Uma cepa de E. faecalis (ATCC 29212) foi reisolada em caldo infusão cérebro-coração (BHI) (Kasvi, Padova, Itália), o qual foi suplementado com $5 \%$ de soro sanguíneo de cavalo desfibrinado (LaborClin, Pinhais, Brasil).

Para a exposição ao microrganismo do estudo, os dentes bovinos, em conjunto com os microtubos, foram adaptados em um frasco tipo penicilina. Tal conjunto foi submerso em 3,0 mL de caldo BHI, de modo que aproximadamente $1 \mathrm{~mm}$ do ápice radicular pudesse ficar submerso nesse meio de cultivo. A união entre o frasco de penicilina, o dispositivo envolvendo o segmento radicular e o microtubo foi 
selada com araldite. Após, procedeu-se à inoculação na parte superior do microtubo com $500 \mu \mathrm{L}$ do inóculo bacteriano padronizado a $5 \times 10^{5} \mathrm{UFC} / \mathrm{mL}$. 0 dispositivo (frasco penicilina, microtubo e segmento radicular) foi incubado a $37^{\circ} \mathrm{C}$ em aerobiose (Figura 1). A infiltração bacteriana foi checada por um período de 14 dias. A cada 7 dias, o caldo BHI foi aspirado do interior do microtubo e uma nova alíquota de caldo BHI foi inserida para dentro do dispositivo.

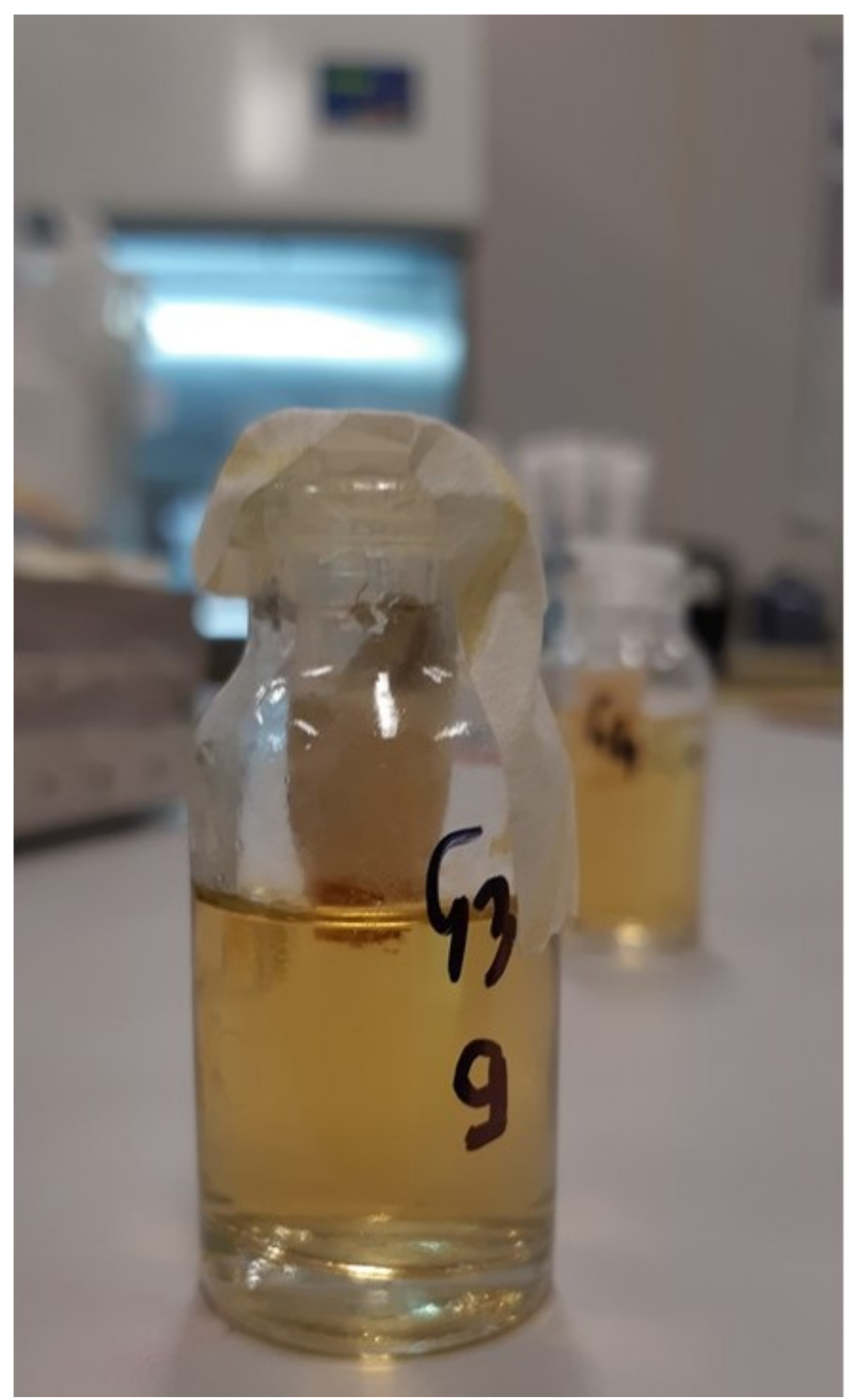

Figura 1. Dispositivo de contaminação microbiológica.

Posteriormente ao período de 14 dias, o conjunto foi desmontado e, subsequentemente, os dentes de todos os grupos foram seccionados no sentido sagital, com o auxílio de um disco diamantado estéril, sendo utilizado um disco estéril para cada dente. Logo após, uma das porções foi imersa em 1,5 mL de Tampão Fosfato-Salino (PBS) (Dinâmica, Diadema, São Paulo) e incubada em aerobiose a $37^{\circ} \mathrm{C}$ durante 24 horas. Posteriormente, a suspensão resultante foi semeada na superfície de placas de Petri com ágar sangue suplementado com $5 \%$ de soro sanguíneo de cavalo desfibrinado. Após, tais placas foram incubadas em aerobiose a $37^{\circ} \mathrm{C}$ por 48 horas, sendo contabilizadas as Unidades Formadoras de Colônia por mililitro (UFC/mL) de forma manual. 


\section{Análise Estatística}

Os dados foram analisados através do software de análise estatística Graph Pad Prism 6.0 (Graph Pad Prism Inc., La Jola, CA, EUA). As diferenças entre os grupos foram analisadas por teste de ANOVA one-way. Para análise da comparação múltipla, realizou-se o teste de Tukey. Os resultados foram considerados estatisticamente significativos quando $P \leq 0,05$. Para este estudo, foi adotado intervalo de confiança de $95 \%$.

\section{RESULTADO}

Ao final dos 14 dias, todos os frascos de penicilina contendo os respectivos dentes bovinos apresentaram turvação do meio de cultivo, indicando que houve a passagem dos microrganismos por meio das obturações. Quanto às quantificações, no G1-FV, a média de recuperação bacteriana foi de $1 \times 10^{10} \mathrm{UFC} / \mathrm{mL}\left(0,9 \times 10^{10}-1,1 \times 10^{10} ; \pm 0,06\right.$; IC $\left.95 \%\right)$. No G2-FC, a sobrevivência bacteriana foi igual a $\mathbf{9 , 0} \times \mathbf{1 0}^{7} \mathrm{UFC} / \mathrm{mL}\left(8,0 \times 10^{7}-9,9 \times 10^{7} ; \pm 5,25 ;\right.$ IC 95\%). Já no G3-Ni-Cr, obteve-se uma recuperação bacteriana igual a 5,2 × $10^{6} \mathrm{UFC} / \mathrm{mL}\left(3,2 \times 10^{6}-7,0 \times 10^{6} ; \pm 1,43\right.$; IC 95\%). No G4-Cu-Al, foi encontrada uma média de 5,7 × $10^{6} \mathrm{UFC} / \mathrm{mL}\left(4,1 \times 10^{6}-7,8 \times 10^{6}\right.$; $\pm 1,30$; IC 95\%). No G5-CN, foi relatada uma sobrevivência bacteriana de $1 \times 10^{15} \mathrm{UFC} / \mathrm{mL}$ $\left(0,89 \times 10^{15}-1,2 \times 10^{15} ; 0,11\right.$; IC 95\%) (Tabela 2).

Tabela 2. Resultados da recuperação bacteriana nos grupos do estudo

\begin{tabular}{cc}
\hline Grupos & Média (mín. - máx.; dp) \\
\hline G1-FV & $1 \times 10^{10} \mathrm{UFC} / \mathrm{mL}\left(0.9 \times 10^{10}-1.1 \times 10^{10} ; \pm 0.06\right)^{\mathrm{A}}$ \\
G2-FC & $9.0 \times 10^{7} \mathrm{UFC} / \mathrm{mL}\left(8.0 \times 10^{7}-9.9 \times 10^{7} ; \pm 5.25\right)^{\mathrm{B}}$ \\
G3-Ni-Cr & $5.2 \times 10^{6} \mathrm{UFC} / \mathrm{mL}\left(3.2 \times 10^{6}-7.0 \times 10^{6} ; \pm 1.43\right)^{\mathrm{C}}$ \\
G4-Cu-Al & $5.7 \times 10^{6} \mathrm{UFC} / \mathrm{mL}\left(4.1 \times 10^{6}-7.8 \times 10^{6} ; \pm 1.30\right)^{\mathrm{C}}$ \\
G5-CN & $1 \times 10^{15} \mathrm{UFC} / \mathrm{mL}\left(0.8 \times 10^{15}-1.2 \times 10^{15} \pm 0.11\right)^{\mathrm{D}}$ \\
\hline
\end{tabular}

Letras diferenças indicam diferença estatisticamente significante $(\mathrm{P} \leq 0,05)$.

Quando comparamos os grupos G1-FV, G2-FC, G3-Ni-Cr e G4-Cu-Al, em relação ao G5-CN, foi observada uma diferença estatisticamente significativa $(P \leq 0,0001)$, uma vez que esta diferença está relacionada a uma diminuição expressiva da recuperação bacteriana encontrada nos grupos-testes. Por sua vez, quando avaliados todos os dentes submetidos aos mesmos procedimentos, porém apresentando retentores intrarradiculares distintos, também se observou uma diferença significativa entre eles, principalmente quando foi comparado o G1-FV aos demais grupos-testes $(P \leq 0,0001)$. Adicionalmente, também foi encontrada diferença significativa no grau de recuperação bacteriana, quando o grupo G2-FC foi comparado aos $\mathrm{G} 3-\mathrm{Ni}-\mathrm{Cr}$ e $\mathrm{G} 4-\mathrm{Cu}-\mathrm{Al}$, os quais foram compostos por retentores metálicos fundidos $(\mathrm{P} \leq 0,0001)$. Quando foram comparados entre si os dois grupos compostos por retentores à base a ligas metálicas (G3-Ni-Cr $\times \mathrm{G} 4-\mathrm{Cu}-\mathrm{Al})$, não foi observada diferença significativa entre eles ( $q=1,52 ;-0,00001598$ a 0,000007177; IC 95\%), ou seja, não foi observada diferença no potencial antibacteriano entre G3-Ni-Cr e G4-Cu-Al (Figura 2). 


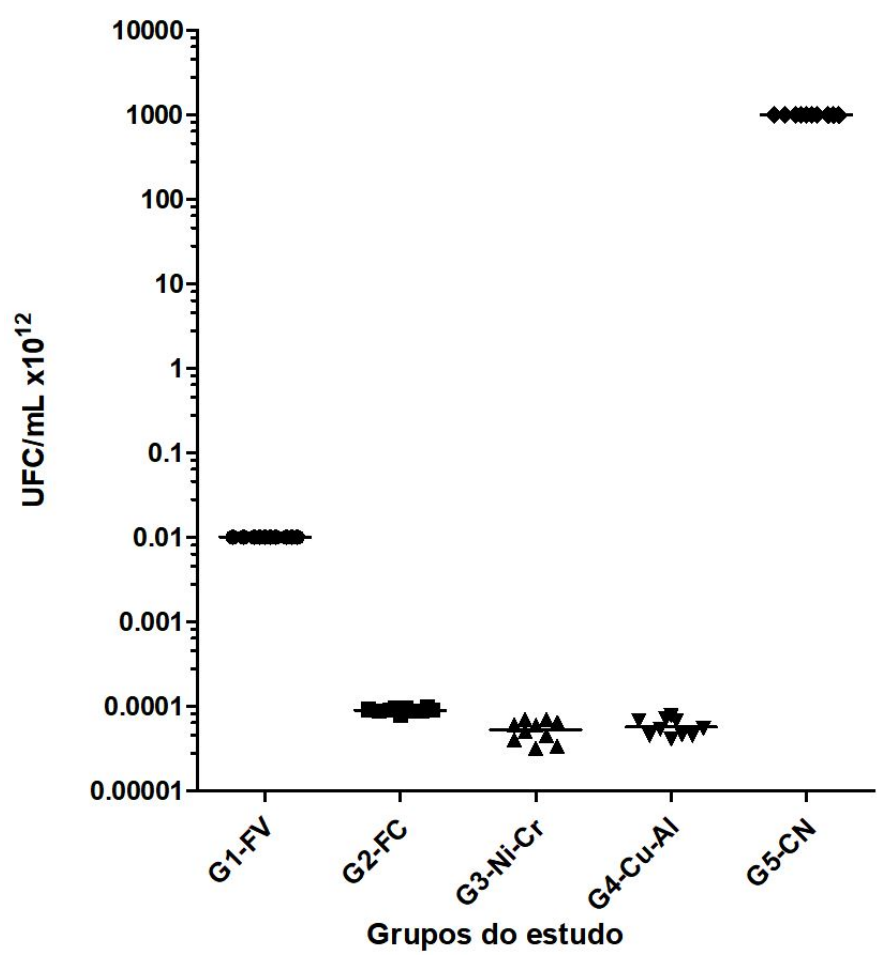

Figura 2. Representação das diferenças dos grupos do estudo.

\section{DISCUSSÃO}

$\mathrm{Na}$ atualidade, estão sendo desenvolvidos diversos protocolos para completa desinfecção do canal radicular, especialmente no que diz respeito ao preparo químico-mecânico. Entretanto, nenhum dos elementos da terapia endodôntica pode garantir $100 \%$ da esterilidade do sistema de canais ${ }^{11,12,23}$. Desta forma, a incorporação de estruturas apresentando características antimicrobianas no canal radicular torna-se um fator primordial na prevenção do recrescimento de bactérias residuais ${ }^{17-19,21-23}$. Sob esta perspectiva, o presente estudo avaliou o potencial antibacteriano de diferentes retentores intrarradiculares frente ao E. faecalis, em dentes bovinos.

No estudo ora apresentado, quando se analisou o pino de fibra de vidro, o nível de recuperação bacteriana foi alto, fato que revela que tal retentor não apresenta um bom potencial antibacteriano frente ao E. faecalis. Nossos resultados concordam com os estudos previamente publicados por Poggio et al. ${ }^{25}$, que também relataram a falta de atividade antimicrobiana quando pinos de fibra de vidro e fibra de quartzo foram avaliados em experimentos in vitro realizados sobre placas de Petri contaminadas, no qual houve medida de halo de inibição bacteriana. Desta forma, observa-se que há uma relação entre dados obtidos por meio de experimentos microbiológicos laboratoriais de modo in vitro e dados obtidos pelo nosso estudo, no qual se testou a capacidade antimicrobiana dos pinos intrarradiculares por meio de experimentos utilizando dentes bovinos. Logo, nossos resultados indicam que este RIR, apesar de ser muito utilizado devido às suas propriedades estéticas e mecânicas, não apresenta uma boa capacidade de inibir o crescimento bacteriano.

Adicionalmente, no estudo aqui apresentado, também se avaliou a capacidade antimicrobiana frente ao E. faecalis dos pinos de fibra de carbono (G2-FC). Surpreendentemente, nossos resultados destacam um potencial antimicrobiano considerável de tal retentor, uma vez que foi aqui observada uma redução de carga bacteriana na ordem oito unidades logarítmicas, em média, quando o G2-FC foi comparado ao G5-CN, o qual não apresentava nenhum RIR. Interessantemente, nossos resultados também assinalaram um potencial antimicrobiano ainda maior, quando os grupos $\mathrm{G} 3-\mathrm{Ni}-\mathrm{Cr}$ e $\mathrm{G} 4-\mathrm{Cu}-\mathrm{Al}$, os quais continham pinos metálicos, foram analisados. Tal fato é comprovado pela diminuição 
expressiva da recuperação bacteriana na ordem de nove unidades logarítmicas, em média, quando comparados G3-Ni-Cr e G4-Cu-Al ao G5-CN, bem como uma diminuição de quatro unidades logarítmicas, quando comparados G3-Ni-Cr e G4-Cu-Al ao G1-FV. Portanto, comprova-se aqui um grande potencial antimicrobiano dos retentores pertencentes aos grupos $\mathrm{G} 3-\mathrm{Ni}-\mathrm{Cr}$ e $\mathrm{G} 4-\mathrm{Cu}-\mathrm{Al}$, uma vez que estes apresentaram uma expressiva capacidade de inibição do crescimento bacteriano em nosso estudo. Entretanto, não podem ser feitas aqui demais comparações devido à falta de estudos que avaliem o potencial antimicrobiano dos retentores intrarradiculares testados em nosso estudo.

Ainda assim, três fatores, apesar de não terem sido abordados no presente estudo, têm efeito significativo no resultado do tratamento endodôntico ${ }^{26}$. Além da qualidade do pino intracanal, estudos publicados por Estrela et al. ${ }^{27}$, Durighetto et al. ${ }^{28}$, Hommez et al. ${ }^{29}$ e Tronstad et al. ${ }^{30}$ verificaram que a ausência da periodontite apical, a qualidade da obturação, bem como a restauração coronária, são considerados fatores clínicos e estes têm demonstrado impacto no sucesso endodôntico. No entanto, estudos que relatam as condutas frente às falhas são escassos na literatura 31 .

Neste contexto, Oliveira et al. ${ }^{31}$ relataram que quando o pino se encontra sob condições satisfatórias, a sua remoção somente é indicada quando há tratamento endodôntico insatisfatório e presença de lesão periapical. Em contrapartida, no contexto de condições insatisfatórias do pino, a sua remoção independe da qualidade do tratamento endodôntico. Desta forma, sob esta condição, o retratamento endodôntico é preconizado independentemente da presença ou não da lesão periapical, uma vez que tais condutas determinarão uma melhor estabilidade para a prótese, além de contribuir para a não fratura da raiz e evita possíveis infiltrações microbianas. No entanto, antes da remoção do pino nos cenários, nos quais não há presença de lesão periapical, deve-se ressaltar que tal possível remoção gera um excessivo enfraquecimento da estrutura dentinária radicular e, nestes casos, a proservação radiográfica poderá ser a primeira escolha de tratamento. Já naqueles cenários, quando há presença de lesão periapical, tal ocorrência torna-se fator determinante para a indicação da cirurgia paraendodôntica.

\section{CONCLUSÃO}

Frente ao estudo desenvolvido, os retentores intrarradiculares constituintes dos grupos $\mathrm{G} 3-\mathrm{Ni}-\mathrm{Cr}$ e G4-Cu-Al foram os que apresentaram maior efeito antimicrobiano frente ao microrganismo testado. Desta forma, confirma-se a possibilidade de empregá-los nas etapas protéticas de confecção da futura restauração, resultando, assim, em maiores índices de sucesso.

\section{REFERÊNCIAS}

1. Dioguardi M, Di Gioia G, Illuzzi G, Arena C, Caponio VCA, Caloro GA, et al. Inspection of the microbiota in endodontic lesions. Dent J (Basel). 2019 May;7(2):1-15. http://dx.doi.org/10.3390/dj7020047. PMid:31052361.

2. Narayanan LL, Vaishnavi C. Endodontic microbiology. J Conserv Dent. 2010 Oct;13(4):233-9. http://dx.doi.org/10.4103/0972-0707.73386. PMid:21217951.

3. Saito D, Leonardo RT, Rodrigues JL, Tsai SM, Höfling JF, Gonçalves RB. Identification of bacteria in endodontic infections by sequence analysis of 16S rDNA clone libraries. J Med Microbiol. 2006 Jan;55(Pt 1):101-7. http://dx.doi.org/10.1099/jmm.0.46212-0. PMid:16388037.

4. Swimberghe RCD, Coenye T, De Moor RJG, Meire MA. Biofilm model systems for root canal disinfection: a literature review. Int Endod J. 2019 May;52(5):604-28. http://dx.doi.org/10.1111/iej.13050. PMid:30488449. 
5. Dioguardi M, Di Gioia G, Illuzzi G, Laneve E, Cocco A, Troiano G. Endodontic irrigants: diferente methods to improve efficacy and related problems. Eur J Dent. 2018 Jul-Sep;12(3):459-66. http://dx.doi.org/10.4103/ejd.ejd_56_18. PMid:30147418.

6. Rocha IJPB, Silva LDR, Santa Maria SL, Oliveira DP, Porfírio Z. Análise de dois métodos de desinfecção de condutos radiculares após preparo para pinos: proposta de protocolo protético: estudo in vitro. Rev Odontol UNESP. 2017 Aug;46(4):189-95. http://dx.doi.org/10.1590/1807-2577.00917.

7. Choi YS, Kim C, Moon JH, Lee JY. Removal and killing of multispecies endodontic biofilms by Nacetylcysteine. Braz J Microbiol. 2018 Jan-Mar;49(1):184-8. http://dx.doi.org/10.1016/j.bjm.2017.04.003. PMid:28916389.

8. Trusewicz M, Buczkowska-Radlinska J, Giedrys-Kalemba S. The effectiveness of some methods in eliminating bacteria from the root canal of a tooth with chronic apical periodontitis. Ann Acad Med Stetin. 2005;51(2):43-8. PMid:16519096.

9. Sagsen B, Zortuk M, Ertas H, Er O, Demirbuga S, Arslan H. In vitro fracture resistance of endodontically treated roots filled with a bonded filling material or diferente types of posts. J Endod. 2013 Nov;39(11):1435-7. http://dx.doi.org/10.1016/j.joen.2013.05.006. PMid:24139269.

10. Zhu Z, Dong XY, He S, Pan X, Tang L. Effect of post placement on the restoration of endodontically treated teeth: a systematic review. Int J Prosthodont. 2015 Sep-Oct;28(5):475-83. http://dx.doi.org/10.11607/ijp.4120. PMid:26340006.

11. Bazvand L, Aminozarbian MG, Farhad A, Noormohammadi H, Hasheminia SM, Mobasherizadeh S. Antibacterial effect of triantibiotic mixture, chlorhexidine gel, and two natural materials Propolis and Aloe vera against Enterococcus faecalis: An ex vivo study. Dent Res J. 2014 Jul;11(4):469-74. PMid:25225560.

12. Kiryu T, Hoshino E, Iwaku M. Bacteria invading periapical cementum. J Endod. 1994 Apr;20(4):169-72. http://dx.doi.org/10.1016/S0099-2399(06)80328-6. PMid:8035155.

13. Fernandes AS, Shetty S, Coutinho I. Factors determining post selection: a literature review. J Prosthet Dent. 2003 Dec;90(6):556-62. http://dx.doi.org/10.1016/j.prosdent.2003.09.006. PMid:14668756.

14. Poggio C, Lombardini M, Colombo M, Dagna A, Saino E, Arciola CR, et al. Antibacterial effects of six endodontic sealers. Int J Artif Organs. 2011 Sep;34(9):908-13. http://dx.doi.org/10.5301/ijao.5000055. PMid:22094573.

15. Almaroof A, Niazi SA, Rojo L, Mannocci F, Deb S. Influence of a polymerizable eugenol derivative on the antibacterial activity and wettability of a resin composite for intracanal post cementation and core build-up restoration. Dent Mater. 2016 Jul;32(7):929-39. http://dx.doi.org/10.1016/j.dental.2016.04.001. PMid:27130610.

16. Kasraei S, Sami L, Hendi S, Alikhani MY, Rezaei-Soufi L, Khamverdi Z. Antibacterial properties of composite resins incorporating silver and zinc oxide nanoparticles on Streptococcus mutans and Lactobacillus. Restor Dent Endod. 2014 May;39(2):109-14. http://dx.doi.org/10.5395/rde.2014.39.2.109. PMid:24790923.

17. Haapasalo M, Endal U, Zandi H, Coil JM. Eradication of endodontic infection by instrumentation and irrigation solutions. Endod Topics. 2005 Mar;10(1):77-102. http://dx.doi.org/10.1111/j.16011546.2005.00135.x.

18. Pizzo G, Giammanco GM, Cumbo E, Nicolosi G, Gallina G. In vitro antibacterial activity of endodontic sealers. J Dent. 2006 Jan;34(1):35-40. http://dx.doi.org/10.1016/j.jdent.2005.03.001. PMid:15907357.

19. Slutzky-Goldberg I, Slutzky H, Solomonov M, Moshonov J, Weiss EI, Matalon S. Antibacterial properties of four endodontic sealers. J Endod. 2008 Jun;34(6):735-8.

http://dx.doi.org/10.1016/j.joen.2008.03.012. PMid:18498902. 
20. Juloski J, Goracci C, Tsintsadze N, Carrabba M, Vichi A, Vulicevic ZR, et al. Influence of luting agent translucency on fiber post retention. Eur J Oral Sci. 2015 Apr;123(2):116-21. http://dx.doi.org/10.1111/eos.12174. PMid:25683864.

21. Souza AC, Gonçalves FC, Anami LC, Melo RM, Bottino MA, Valandro LF. Influence of insertion techniques for resin cement and mechanical cycling on the bond strength between fiber posts and root dentin. J Adhes Dent. 2015 Apr;17(2):175-80. http://dx.doi.org/10.3290/j.jad.a33993. PMid:25859568.

22. Komada W, Inagaki T, Ueda Y, Omori S, Hosaka K, Tagami J, et al. Influence of water immersion on the mechanical properties of fiber posts. J Prosthodont Res. 2017 Jan;61(1):73-80. http://dx.doi.org/10.1016/j.jpor.2016.05.005. PMid:27324293.

23. Novais VR, Rodrigues RB, Simamoto PC Jr, Lourenço CS, Soares CJ. Correlation between the mechanical properties and structural characteristics of different fiber posts systems. Braz Dent J. 2016 JanFeb;27(1):46-51. http://dx.doi.org/10.1590/0103-6440201600377. PMid:27007345.

24. Haapasalo M, Orstavik D. In vitro infection and disinfection of dentinal tubules. J Dent Res. 1987 Aug;66(8):1375-9. http://dx.doi.org/10.1177/00220345870660081801. PMid:3114347.

25. Poggio C, Trovati F, Ceci M, Chiesa M, Colombo M, Pietrocola G. Biological and antibacterial properties of a new silver fiber post: in vitro evaluation. J Clin Exp Dent. 2017 Mar;9(3):e387-93. http://dx.doi.org/10.4317/jced.53464.

26. Ng YL, Mann V, Rahbaran S, Lewsey J, Gulabivala K. Outcome of primary root canal treatment: systematic review of the literature-Part 2. Influence of clinical factors. Int Endod J. 2008 Jan;41(1):631. http://dx.doi.org/10.1111/j.1365-2591.2007.01323.x. PMid:17931388.

27. Estrela C, Bueno MR, Porto OC, Rodrigues CD, Pécora JD. Influence of intracanal post on apical periodontitis identified by cone-beam computed tomography. Braz Dent J. 2009;20(5):370-5. http://dx.doi.org/10.1590/S0103-64402009000500003. PMid:20126904.

28. Durighetto IL, Biffi JCG, Júnior AFD, Caram CM. Avaliação das características da contenção intraradicular e tratamentos endodônticos em radiografias periapicais de 1000 dentes. Cienc Odontol Bras. 2007;10(2):31-9. http://dx.doi.org/10.14295/bds.2007.v10i2.336.

29. Hommez GM, Coppens CR, De Moor RJ. Periapical health related to the quality of coronal restorations and root fillings. Int Endod J. 2002 Aug;35(8):680-9. http://dx.doi.org/10.1046/j.13652591.2002.00546.x. PMid:12196221.

30. Tronstad L, Asbjørnsen K, Døving L, Pedersen I, Eriksen HM. Influence of coronal restorations on the periapical health of endodontically treated teeth. Endod Dent Traumatol. 2000 0ct;16(5):218-21. http://dx.doi.org/10.1034/j.1600-9657.2000.016005218.x. PMid:11202885.

31. Oliveira MAVC, Mesquita GC, Biffi JCG. Retratamento endodôntico de dentes com contenção intrarradicular: orientação clínica. Rev Odontol Bras Central. 2011;20(53):146-50.

\section{CONFLITOS DE INTERESSE}

Os autores declaram não haver conflitos de interesse.

\section{*AUTOR PARA CORRESPONDÊNCIA}

Alexandra Flávia Gazzoni, Rua Os dezoito do Forte, 2366, Bairro São Pelegrino, Caxias do SulRS, Brasil, e-mail: alexandra.gazzoni@fsg.edu.br

Recebido: Maio 16, 2019

Aprovado: Agosto 7, 2019 